\title{
LA DESCENTRALIZACIÓN FISCAL EN AMÉRICA LATINA. BALANCE DE UN PROCESO
}

\author{
Diego E. Pinilla* \\ Juan de Dios Jiménez** \\ Roberto Montero***
}

Ta descentralización redefinió las políticas públicas en América muchos componentes de la política social están a cargo de gobiernos subnacionales (GS), con el convencimiento de que obtendrán mejores resultados de bienestar social. La intensa descentralización de las últimas décadas no ha seguido un curso lineal. La sobredeterminación política y una multitud de factores influyen en su heterogeneidad. Pero, en diverso grado, la literatura identifica algunas características comunes que responden a una lógica general.

Este artículo examina las particularidades relacionadas con el origen del proceso, su evolución y sus principales desafíos ${ }^{1}$. Además, presenta un ejercicio cuantitativo que intenta superar las dificultades para dar una visión fiscal comparativa de los países de América Latina y de sus niveles subnacionales. Recurriendo a nuevas bases de datos y consultando un gran número de fuentes se construyó un panel no balanceado del ingreso público subcentral total como porcentaje del

* Doctor en Economía y docente investigador de la Universidad Nacional de Chimborazo, Ecuador, [dpinilla@unach.edu.ec].

** Doctor en Economía y catedrático de Economía Aplicada, Universidad de Granada, España, [juande@ugr.es].

*** Doctor en Economía y profesor titular de Economía Aplicada, Universidad de Granada, España, [montero@ugr.es]. Fecha de recepción: 4 de marzo de 2014, fecha de modificación: 1 de agosto de 2014, fecha de aceptación: 29 de octubre de 2015. Sugerencia de citación: Pinilla, D. E.; J. D. Jiménez y R. Montero. "La descentralización fiscal en América Latina. Balance de un proceso", Revista de Economia Institucional 17, 33, 2015, pp. 133-160. DOI: http://dx.doi. org/10.18601/01245996.v17n33.06

${ }_{1}$ Aghón (1997) analiza las dificultades para hacer una caracterización global de la descentralización en la región. Descentralización es, por antonomasia, la "aceptación de la diversidad de experiencias", y la combinación óptima de políticas depende de las características de cada país. 
PIB y del ingreso público total de 17 países para la mayoría de los años del periodo 1990-2009. Periodo que se escogió no solo por la disponibilidad de información sino porque es el de implementación y consolidación del proceso.

La primera sección muestra que la descentralización tuvo como antecedente la liberalización política y económica de estas sociedades cada vez más urbanas. La segunda sección presenta una descripción cuantitativa desde el punto de vista fiscal e intenta explicar las diferencias en la intensidad del proceso con base en algunos factores objetivos. En la tercera y la cuarta se describen la primera y la segunda generación de reformas, la configuración de los sistemas de transferencias, los inconvenientes que surgieron y los intentos de establecer incentivos institucionales adecuados. Por último se presentan las conclusiones.

\section{ORÍGENES DE LA DESCENTRALIZACIÓN}

Uno de los principales hechos sociales que precedieron y dieron marco a la descentralización fue la notable urbanización que ocurrió entre los años sesenta y ochenta del siglo pasado. En ese periodo, el 90\% del crecimiento demográfico de América Latina se presentó en las ciudades ${ }^{2}$. La creciente demanda de servicios básicos urbanos y la intensa migración a las ciudades provocaron grandes demandas locales que desafiaron la configuración centralizada tradicional ${ }^{3}$. Los problemas de gestión ya eran evidentes en los años setenta ${ }^{4}$, empezando por la falta de recursos locales para proporcionar los servicios más elementales. La prolongada tradición centralista había fomentado gobiernos locales sin autonomía y con baja capacidad administrativa, y en la mayoría de los países estas deficiencias llevaron a reformar las normas de ordenamiento municipal, muchas de

${ }^{2}$ Según Artana (2007), en América Latina hay más de 100 gobiernos estatales y unos 14.000 municipios. E1 30\% de ellos tiene menos de 5.000 habitantes y el $90 \%$ menos de 50.000. Existen varias macro ciudades, y más del $75 \%$ de la población vive en zonas urbanas, de modo que es una de las regiones más urbanizadas del mundo.

${ }^{3}$ Franco (2004) da una explicación opuesta: la creación de grandes centros urbanos promueve la gestión centralizada en vez de fomentar la descentralización.

${ }^{4}$ En América Latina (17 países), el porcentaje promedio de población urbana pasó del 46,1\% en 1969 al 60,5\% en 1985 (World Bank). Si bien entre 1980 y 1990 el número de municipios aumentó, algunos de sus indicadores están muy alejados de los de Europa, donde hay un municipio por cada $199 \mathrm{~km}^{2}$, mientras que en América Latina hay uno por cada $1.338 \mathrm{~km}^{2}$, en general de carácter rural, pues cerca del $80 \%$ tiene menos de 25 mil habitantes y solo el $0,1 \%$ (71 municipios) más de 500 mil. Además, en ellos existe un gran vacío institucional y bajo acceso a los centros de decisión y a servicios públicos (Victory, 1999). 
ellas vigentes desde el siglo XIX (Nickson, 1995; Espitia, 2004) ${ }^{5}$. Era clara la inoperancia del modelo centralista para enfrentar la creciente complejidad del mundo local y urbano: "la crisis del centralismo fue ante todo una crisis de eficiencia” (Finot, 2001). El centro era vez más lejano, lo que favorecía el clientelismo y la corrupción. Para el ciudadano común, el gobierno era incapaz de atender sus necesidades cotidianas.

Sin desconocer el papel del desarrollo urbano, existe consenso teórico sobre las numerosas causas de la profundización del proceso. Diversos factores contribuyeron a debilitar el centralismo y a elaborar argumentos en favor de la descentralización, un proceso tan amplio y complejo que no lo puede explicar un solo factor (ibíd.). Además, como ocurre con otros conceptos teóricos, el de "descentralización" se puede interpretar de diferentes maneras y, dependiendo de la definición, puede ser parcial o totalmente realizado. Quizá ello explique el entusiasmo que provocó y los beneficios que prometía (Mascareño, 2009), sin importar la ubicación en el espectro político o ideológico (Bardhan, 2002). Había un gran consenso político sobre la necesidad de descentralizar, que se reflejó en la expedición de normas que ordenaban significativas transferencias de ingresos y competencias a los GS (Aghón, 1997), y se compartía la convicción de que era necesario organizarse de otra manera ante la caducidad del modelo anterior (Finot, 1998). El impulso descentralizador fue entonces producto de una conjunción de intereses: los de quienes proponían recurrir al mercado para superar el déficit fiscal, los de nuevos gestores públicos que aspiraban a reducir los costos de transacción y hacer más eficiente la prestación de servicios públicos, y los de una generación de actores sociales y políticos con nuevas concepciones de la democracia (Nickson, 1995; Fleury, 1999; Assies, 2003).

\section{ENFOQUE POLÍTICO DEMOCRATIZADOR}

Aunque en la descentralización que se inició en los ochenta incidieron diversos factores, la política fue la fuerza impulsora dominante, como expresión de la necesidad de profundizar la democracia (Rojas, 1998; Burki et al., 1999). La descentralización fue parte fundamental de la transformación de los sistemas políticos latinoamericanos

${ }^{5}$ En Perú la Ley de Municipalidades de 1984 sustituyó a una serie de leyes vigentes desde 1892. Se promulgaron nuevos códigos municipales en Venezuela (1978), Bolivia (1985), Colombia (1986), Paraguay (1987) y Nicaragua (1988). En México (1983) y Guatemala (1986) se enmendaron artículos de la Constitución (Nickson, 2005). 
(Restrepo, 2006) ${ }^{6}$, cuyo objetivo era acercar el gobierno a los ciudadanos para lograr mayor transparencia y un verdadero control de la gestión pública (Mascareño, 2009). La participación ciudadana y la organización de la sociedad civil darían voz a las masas relegadas por el modelo centralista (Bervejillo, 1991; Daughters y Harper, 2007), así como autonomía y competencia política, mediante una "revolución silenciosa" (Campbell, 2003). Los discursos de democracia y descentralización se mezclaban en ideas y aspiraciones tales como participación, transparencia, eficacia, equidad, sociedad civil, y se convirtieron en bases argumentales para señalar las bondades de una y otra (Mascareño, 2009).

Por ello, algunos autores (como Rojas, 1999), al estudiar las causas de la descentralización, señalan que el factor político fue definitivo. Sus motivaciones fueron en esencia de carácter político: restaurar la democracia, resolver conflictos internos, multiplicar los centros de poder o reorganizar la sociedad civil. El Banco Mundial comparte esa idea: "En esencia, la política es la fuerza dominante que motiva la descentralización, ya que esta forma parte de una tendencia más generalizada hacia la democracia en la región" (Burki et al., 1999). Se concordaba en que el desarrollo de la democracia requería descentralizar (Mascareño, 2009), con una visión político-ideológica que pretendía cambiar el Estado centralizado autoritario por uno descentralizado democrático, que acercara el poder al ciudadano y rompiera con el autoritarismo de la administración central. La descentralización contribuiría a fortalecer las nacientes democracias o a superar la crisis de legitimidad y gobernabilidad de las ya consolidadas. El poder público se debía redistribuir y las competencias del gobierno central se debían transferir a los centros locales.

La descentralización política se llevó a cabo mediante grandes y variadas reformas legales, como la adopción de nuevas constituciones ${ }^{7}$ o reformando las existentes ${ }^{8}$. La mayoría de las reformas cambiaron visiblemente la comprensión del término unidad nacional, que no se conseguiría ignorando las diferencias sino reconociéndolas. Esto indujo cambios sustanciales en los mecanismos de participación y organización política y territorial. Las reformas fortalecieron la descentralización ordenando constitucionalmente la elección democrática

${ }^{6}$ Según Restrepo la restauración de la autonomía relativa entre las ramas del poder público y la ampliación de los derechos políticos y sociales se regaron como aceite en el continente.

7 Brasil en 1988, Colombia en 1991, Paraguay en 1992, Ecuador en 1998 y 2008, Perú en 1993, Venezuela en 1999 y Bolivia en 2009.

${ }^{8}$ Costa Rica en 1989, México en 1992, Argentina en 1994 y Nicaragua en 1995. 
de funcionarios locales o estableciendo mecanismos para dar mayor poder económico a las autoridades locales (Uprimny, 2011).

\section{ENFOQUE ECONÓMICO LIBERALIZADOR}

Para algunos autores, como Falleti (2005), la descentralización se inició en el contexto de reformas estatales (la transición de un Estado desarrollista a uno orientado al mercado). Junto a la explicación política, otro enfoque considera que esta fue parte fundamental de las reformas estructurales del sector público latinoamericano en el marco de la globalización. Siguiendo a Alesina et al. (2000) podemos decir que el vínculo entre descentralización y globalización se basa en la relación entre tamaño del mercado, productividad y restricciones comerciales. Si el tamaño del mercado influye en la productividad, en un mundo de restricciones comerciales las fronteras políticas influyen en el tamaño del mercado y la dimensión de un país es determinante de su nivel de productividad. Sin restricciones comerciales el tamaño de los países se vuelve irrelevante, y la globalización de los mercados hace factible, y en muchos casos promueve, la división política.

En el marco de la globalización se considera perjudicial toda intervención estatal porque crea distorsiones que impiden la eficiente asignación de recursos. La descentralización hace posible que las localidades tomen decisiones de gasto y financiación, introduce criterios de mercado en las decisiones públicas, aumenta la rendición de cuentas y la competencia electoral en sistemas democráticos (Penfold, 2000), en un mundo donde el tamaño de la jurisdicción se torna irrelevante. De sistemas donde el proveedor era público y prácticamente único se pasa a sistemas de múltiples oferentes, y se necesita crear "mercados políticos" que revelen mejor las preferencias de la comunidad (Musgrave y Musgrave, 1992). La descentralización abre nuevos espacios a la inversión privada, reduce las barreras de entrada al capital y promueve el desarrollo de las ventajas competitivas locales, mediante la rivalidad o la emulación. La capacidad de innovación no queda en cabeza exclusiva del Estado burocrático sino dispersa en toda la sociedad; y se deben establecer mecanismos que contribuyan al afloramiento de esas capacidades (Franco, 2004).

Sin duda, la descentralización fue un pilar fundamental de la modernización del Estado que se complementó con otras reformas (Aghón, 1997), y permitiría lograr varios objetivos: eficiencia, mayor equidad, menor corrupción y equilibrio fiscal. En suma, el intenso proceso de urbanización, la ineficiencia del modelo centralista, las crisis fiscales y la liberalización determinaron o promovieron la des- 
centralización en América Latina, y esta era una condición para profundizar la democracia (explicación política) y parte fundamental de un nuevo paradigma (explicación económico-estructural e ideológica).

\section{LA DESCENTRALIZACIÓN FISCAL}

La descentralización fiscal se inició con algún retraso, en comparación con otras regiones, pero una vez comenzó se desarrolló continuamente, según las peculiaridades de cada país. En la evaluación de las dimensiones y avances del proceso hay inconvenientes prácticos, debidos a las interpretaciones conceptuales y la disponibilidad de información (Ebel y Yilmaz, 2003; Artana, 2007). Hay grandes diferencias en el acceso y en la calidad de los sistemas de información de los países, y más a nivel subnacional. Los indicadores comunes de las bases de datos más utilizadas solo están disponibles para algunos países, y solo para uno o varios años?.

Para superar estos inconvenientes se consultó el mayor número posible de fuentes para construir, contrastar o verificar la confiabilidad de los datos. La homogeneidad y comparabilidad de la muestra se garantizó velando por que el indicador elegido se refiriera a todos los países y años, al mismo aspecto económico y a los mismos niveles institucionales. También se tuvieron en cuenta la coincidencia de los datos y el rigor de la fuente (ver el Anexo 1). A partir de esas fuentes, con datos nacionales, se construyeron las variables del ingreso público subcentral total, como porcentaje del PIB y del ingreso del gobierno general de 17 países para la mayoría de los años del periodo 1990$2009^{10}$. Si bien estas variables no representan unívocamente el nivel real de autonomía fiscal, lo representan en forma indirecta y aproximada; son buenos indicadores del peso de los GS en el sector público y en la economía en general. Se prefirió tomar el ingreso subcentral (en vez del gasto, p. ej.) porque su comportamiento recoge mejor el fortalecimiento tributario local y guarda más relación con los incentivos positivos de la descentralización (control ciudadano, competencia entre jurisdicciones, mayor cercanía entre costos y beneficios).

Para el panel no balanceado resultante se obtuvo un ingreso subcentral promedio del $4,26 \%$ del PIB para todo el periodo. Este prome-

${ }^{9}$ La mayoría de los trabajos cuantitativos sobre la descentralización en América Latina y el mundo en general recurren al Government Finance Statistics del FMI.

10 América Latina existe como conjunto y tiene cierta unidad, con un estilo particular de desarrollo, racionalismo económico y movilización política y social (Touraine, 1989); por tanto, hay razones para decir que los países que incluimos son una muestra relativamente homogénea: Argentina, Bolivia, Brasil, Chile, Colombia, Costa Rica, Ecuador, E1 Salvador, Guatemala, Honduras, México, Nicaragua, Panamá, Paraguay, Perú, Venezuela y Uruguay. 
dio oculta grandes diferencias en el nivel de descentralización de los países. Por ejemplo, en 2009 los países con mayor proporción fueron Argentina (14,6\%) y Brasil (14,1\%). En Bolivia, México, Colombia y Venezuela varió entre el 11\% y el 7\%. En los demás fue inferior al promedio ${ }^{11}$. Como se observa en la gráfica 1 , hubo apreciables avances en la mayoría de ellos, sobre todo en Argentina, Bolivia, México y Colombia, donde se duplicó el peso de los ingresos de sus sectores territoriales con respecto al PIB. Al contrario de Costa Rica, Panamá y Paraguay, cuyo nivel de descentralización es mínimo e hicieron pocos avances.

Gráfica 1

Ingreso público subcentral en América Latina (17 países), 1990, 2000 y 2009 (Porcentaje del PIB)

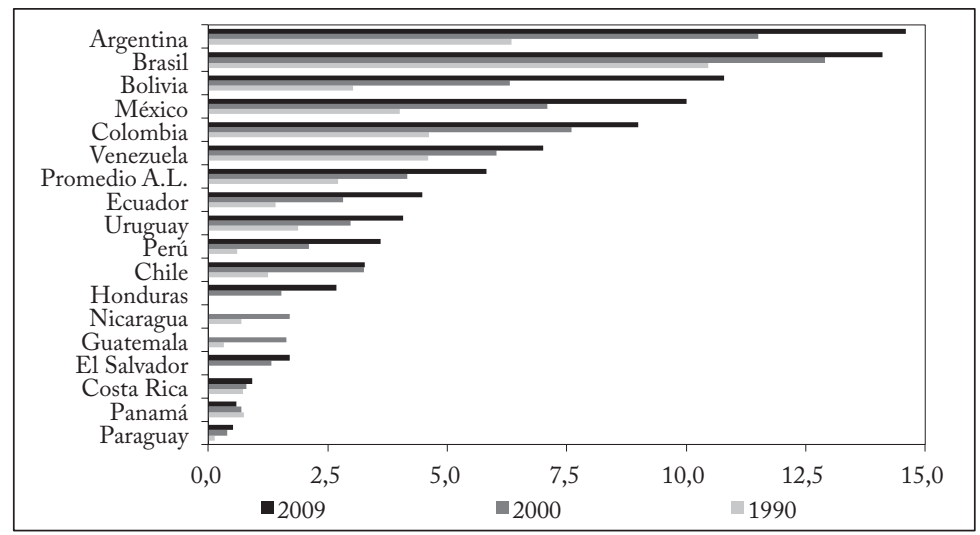

Fuentes: Cepal (2007, 2010); World Bank (2001) para la mayoría de países y años; otras fuentes: Banco del Estado, Ecuador (2009); Eguino et al. (2002); World Bank (2012); Vargas (2013); FMI (2004); Contraloría General de Panamá (2009); Michelin (1999); BID (2009); Mascareño (2000); y cálculos propios a partir de fuentes nacionales y Cepalstat.

Es posible identificar algunas características que expliquen estas diferencias en la descentralización fiscal y en los avances logrados en el periodo. Si bien las relaciones fiscales intergubernamentales suelen ser el resultado de negociaciones impredecibles (Oates, 1977) ${ }^{12}$, para autores como Panizza es más productivo identificar algunas razones objetivas que expliquen el nivel de descentralización, entre ellas el área del país, el nivel de ingreso, la heterogeneidad (étnico-lingüística) y la calidad de la democracia. Usando varios métodos econométricos y mediante estimaciones de corte transversal para una muestra heterogé-

${ }^{11}$ Los valores de Nicaragua y Guatemala corresponden al último año disponible.

12 Es abundante y creciente la literatura sobre los factores que explican las diferencias en el nivel de descentralización entre países, pero los resultados no son concluyentes; ver Arzaghi y Henderson (2005) y Letelier (2005). 
nea de 60 países y tres años, Panizza (1999) encuentra que el tamaño del país, el ingreso per cápita, el fraccionamiento étnico y el nivel de democracia se correlacionan positivamente con la descentralización fiscal, y el área y el PIB per cápita en forma más robusta.

Siguiendo ese trabajo hicimos un ejercicio puramente aproximativo, sin mayores pretensiones y limitado por el tamaño de la muestra (corte transversal de 17 países), en el que usamos MCO para relacionar la descentralización (ingreso público subcentral como porcentaje del PIB), con el tamaño del país, el PIB per cápita anual a precios constantes, un índice de fraccionamiento étnico (Alesina et al., 2000) y uno de calidad democrática (Freedom House). Encontramos, con buen nivel de ajuste, que el tamaño del país es una variable explicativa robusta del nivel de descentralización y de sus avances en las últimas décadas: con un alto coeficiente positivo y una significación superior a1 95\%. Las demás variables no parecen tener relación con el nivel de descentralización. Este resultado ya había sido sugerido por la grafica 1 , donde los países con mayor descentralización fiscal son los países de mayor área geográfica.

\section{REFORMAS DE PRIMERA GENERACIÓN}

Se pueden identificar dos grandes periodos en el proceso latinoamericano de descentralización fiscal (Wiesner, 2003). E1 de "primera generación” se inició a comienzos de los ochenta y se caracterizó por la ejecución de grandes reformas legales que establecieron sistemas amplios y automáticos de transferencias de recursos a los $\mathrm{GS}^{13}$, con cuantías mínimas determinadas mediante fórmulas de distribución a sectores específicos (como salud y educación) y grupos de bajos ingresos. Hubo descentralización de recursos y responsabilidades y se delegó limitada autoridad con respecto a impuestos y gastos. Cabe aclarar que la descentralización no es un estadio sino una secuencia en la que se transfieren responsabilidades y recursos del sector central al subcentral, y se evalúa, corrige y continúa el proceso. En este primer ciclo, que se desarrolló en un contexto de alta inflación y crisis de la deuda, se buscó reducir el tamaño del gobierno central, eliminar el déficit fiscal y promover los mecanismos de mercado. Se trasladó la prestación de algunos servicios públicos y se garantizaron recursos a los GS.

\footnotetext{
${ }^{13}$ Nickson (1998) señala que estas amplias y reglamentadas transferencias difieren de las que existían antes (hasta finales de los setenta), que eran mínimas, se repartían según un criterio discrecional (clientelista) y estaban sujetas a variaciones repentinas.
} 
En un primer momento, la descentralización fue ante todo un proceso político y de reforma estructural, impulsado por la idea de que un sistema de gobiernos locales era económica y políticamente más provechoso. Esta idea, que se adoptó sin cuestionamientos y con extremo optimismo, convirtió a la descentralización en un fin en sî mismo y no en el medio que es realmente. La anhelada autonomía de las jurisdicciones locales se obtendría con la garantía (en muchos casos constitucional) de grandes recursos fiscales que les debía trasladar el gobierno central. Es obvio entonces que las transferencias se convirtieran en el principal instrumento de la descentralización. Un porcentaje fijo del ingreso corriente de los países se convirtió en un derecho subjetivo de los entes locales. Los criterios para determinar su cuantía fueron principalmente la población, la pobreza, la desigualdad social y el bajo desarrollo local. En la mayoría de los países, las transferencias no eran de "libre disponibilidad"; solían ir acompañadas de condiciones, como gastos operativos máximos y gastos sociales mínimos e inversión en infraestructura.

Son paradigmáticos los casos de Colombia y Brasil. En Brasil la Constitución estableció el "recaudo participable", por el cual los gobiernos locales recibirían recursos garantizados, como proporción de los impuestos federales y estatales. En Colombia, la Constitución de 1991 introdujo la participación local en los ingresos fiscales de la nación, que crecería por etapas hasta el $41 \%$ en $2001^{14}$. Bolivia fue otro caso "radical" de descentralización fiscal (Finot, 1998); como señala Oxhorn (2004), la Ley de Participación Popular organizó el país en 311 jurisdicciones, con la responsabilidad de administrar los principales rubros de inversión social. Para cubrir los costos se duplicó el porcentaje de los ingresos que se compartirían con los gobiernos locales, hasta un $20 \%$.

La participación local en el ingreso fiscal de la nación también habría de crecer en Guatemala (e1 8\% según la Constitución de 1985), Honduras (el Código Municipal de 1990 estableció el 5\%) y República Dominicana (la Ley de 1983 asignó el 20\% de los rendimientos de los impuestos nacionales a los gobiernos locales). En México, los estados recibieron una proporción de los impuestos federales que creció por etapas hasta el 21\% en 1994. Y se les requirió que transfirieran el 20\% de esos rendimientos a los municipios. En Perú, mediante un acuerdo de recaudo de 1985, el gobierno local recibió los rendimientos de un recargo al impuesto de ventas nacional, de venta de propiedades y de

\footnotetext{
${ }^{14} \mathrm{E} 1$ programa de transferencias y participaciones en los ingresos corrientes de la nación que estableció la Constitución de 1991 ha sido limitado por la reformas constitucionales de 1995, 2001 y 2007.
} 
compra de vehículos, y de las cuotas de autopistas. En Venezuela una ley de descentralización de 1989 elevó las transferencias del gobierno federal a los gobiernos locales. La excepción a este proceder fue Chile, que favoreció la descentralización selectiva y sectorial más que la entrega de recursos y competencias (Wiesner, 2003).

Tal como se ha descrito, el primer error del proceso fue su secuencia. Primero se establecieron las metas de descentralización del gasto, y solo después se determinó cómo ligar los ingresos transferidos a mayores responsabilidades de los GS ${ }^{15}$. Uno de los principales desaciertos de este periodo fue dar prioridad "a cualquier precio" al reparto de recursos sin contraprestación, en vez de alentar el proceso con incentivos adecuados. Al final, esta prioridad dio lugar a duplicidad de funciones, dificultó la rendición de cuentas y deterioró las estructuras de governanza. Pues al inicio del proceso se dio más importancia a las justificaciones teóricas e ideológicas que a precisar las responsabilidades y los recursos globales y de cada nivel de gobierno. Sin claridad sobre la relación entre recursos y competencias, las fórmulas de distribución de las transferencias no podían asegurar una relación adecuada entre los recursos asignados a un sector dado de una jurisdicción y los costos de prestación del servicio. Las transferencias repartidas con criterios generales que luego se asignan a cada sector según porcentajes predefinidos no garantizan la prestación eficiente de los servicios correspondientes (Ocampo, 1995).

La descentralización por la vía del gasto dio impulso a GS que ejecutaban pero no recaudaban sus ingresos, y a la falta de correspondencia entre ingresos y responsabilidades de gasto, una premisa básica de todo proceso de descentralización. En América Latina las fuentes de ingresos aún son muy centralizadas. Donde había un sistema tributario local, era rígido, las tarifas eran uniformes y se fijaban centralmente a partir de valores fijos y desactualizados; los impuestos eran excesivos, obsoletos y difíciles de administrar, y había muy poca capacidad para recaudarlos. En suma, la presión tributaria local era baja o inexistente (Aghón, 1997). La descentralización fue abiertamente asimétrica con respecto a las responsabilidades. Los niveles locales querían recibir más recursos pero no nuevas responsabilidades, y el nivel central buscaba desprenderse de competencias sin darles mayor autonomía tributaria (Aghón, 1999).

15 En Venezuela no se calculó el impacto fiscal ni macroeconómico de la descentralización cuando se expidió la Ley Orgánica de la Descentralización (LOD). Las autoridades económicas empezaron a preocuparse por la financiación y a involucrarse en el proceso meses después de entrar en vigencia la LOD. Algo semejante ocurrió en Colombia y Brasil (Rojas, 1995). 
Al final, el acento en las transferencias nacionales desincentivó el esfuerzo fiscal propio (Wiesner, 1992) ${ }^{16}$. La mayoría de las entidades locales se volvió sumamente dependiente de las transferencias que se repartían en forma automática y en creciente cantidad, sin ninguna condición ${ }^{17}$. La descentralización solo tiene sentido si los ingresos locales crecen a un ritmo similar al del ingreso nacional (Wiesner, 2002). Para ligar la participación y el control ciudadano al logro de la eficiencia (dos objetivos de la descentralización) y que entre ellas se cree un vínculo "sinérgico", el gasto público se debe atar a la obligación de participar en su financiación (Finot, 1998). Pese al dogma reiterado, la descentralización a menudo amplía la brecha entre las decisiones de gasto y el costo; así sucede cuando el gasto local se financia ante todo con transferencias del gobierno central, como ocurrió en gran parte de América Latina (Burki et al., 1999). La responsabilidad se desdibuja paulatinamente con un sistema de transferencias de destinación específica y falta de ingresos propios. Sin incentivos, no importa cuán eficientes sean los sistemas de información y gestión, pues nadie es responsable de los recursos recibidos y de cumplir los fines sociales (Finot, 2005; Ahmad y García, 2010).

La falta de correspondencia entre gasto local y esfuerzo tributario propio aumentó (o al menos no redujo) la brecha entre instituciones y ciudadanos, al contrario de lo que prometía la descentralización. E1 logro de la eficiencia en el manejo de los recursos sometiendo los servicios públicos a un escrutinio más directo de los ciudadanos no es posible si estos no los ven como un patrimonio colectivo. Al no sufragar su costo, los consideran ajenos y a cargo de la administración lejana que los sigue financiando. La participación ciudadana en la gestión pública no ocurrió en los términos y niveles anunciados porque, además, faltaron canales reales, no solo formales, para alentar la participación. Se improvisaron diversos mecanismos, sin mucho éxito dados los profundos déficits democráticos y de formación cívica a nivel local (Rojas, 1995). Fue "una descentralización sin pueblo" (Castro, 2010), que fortaleció administrativa y fiscalmente a los GS pero no transformó las reglas políticas. Los viejos actores no cambiaron sus reglas ni sus prácticas.

\footnotetext{
${ }^{16}$ Es diferente que haya desconexión entre responsabilidades e ingresos locales propios y que las transferencias promuevan la pereza fiscal del gobierno local. Finot (1998) no encuentra evidencia de que mayores transferencias desincentiven la generación de ingresos locales.

${ }^{17}$ Las transferencias desestimulan el esfuerzo fiscal propio. Sin condiciones, se adhieren al presupuesto local, y los agentes locales gastan más, lo que se conoce como flypaper effect.
} 
Además, algunas entidades territoriales tenían muy baja capacidad de gestión para asumir nuevas responsabilidades y orientar los recursos para impulsar su desarrollo ${ }^{18}$. Era necesario mejorar la administración de los GS, pues para una descentralización fiscal efectiva se requiere al menos crear unidades responsables, actualizar la tecnología, desarrollar sistemas orientados a resultados, y mecanismos de planeación y control modernos. Muchos GS asumieron las nuevas funciones con las viejas estructuras organizativas, y la eficiencia presupuestal retrocedió (Cabrero, 2006).

Esta manera de llevar a cabo la descentralización suscitó varios inconvenientes, el principal de ellos graves problemas fiscales en Argentina, Bolivia, Brasil, Colombia, Ecuador, México y Venezuela. A medida que el proceso avanzaba era más evidente que se había sobrestimado como mecanismo de ajuste fiscal. La experiencia confirmó que la transferencia de competencias de gasto a las entidades locales no era tan beneficiosa para las cuentas públicas como se esperaba, debido en parte a que, por falta de claridad, las transferencias terminaron provocando cuantiosos déficits subnacionales y rescates periódicos a los gobiernos locales más endeudados. Las cuentas fiscales empeoraron en los años noventa y a comienzos de siglo, y el gasto público como porcentaje del PIB creció en forma continua.

Así, aunque no fue la única causa, en su etapa inicial la descentralización agravó los desequilibrios macroeconómicos en momentos de intensas presiones para trasladar grandes volúmenes de recursos y de algunas competencias del centro a los gobiernos locales ${ }^{19}$. Según Wiesner (2003), en la mayoría de los países las transferencias del gobierno nacional a los GS crecieron más rápidamente que el gasto público total, los ingresos tributarios no crecieron a la misma velocidad y los déficits fiscales aumentaron. Aunque, en principio, la transferencia de responsabilidades y recursos debía haber sido fiscalmente neutra, en la mayoría de los casos el efecto neto fue un aumento del gasto total y un debilitamiento de los balances fiscales. Surgen grandes déficits cuando los gobiernos son incapaces de reducir el gasto o aumentar los impuestos para enfrentar el costo creciente de las transferencias.

Además la descentralización entorpeció la capacidad del gobierno para responder a la volatilidad económica. La descentralización fiscal,

\footnotetext{
${ }_{18}$ Aunque en algunas entidades territoriales colombianas la autonomía ha mejorado visiblemente la gestión pública (Ocampo, 1995). Por tanto, la respuesta no es mantener las responsabilidades en cabeza del gobierno central o revertir la transferencia de funciones realizada sino garantizar el apoyo eficaz a esta transferencia y al control ciudadano.

${ }^{19}$ Los casos más representativos fueron Argentina, Brasil y Colombia (Aghón, 1997).
} 
bien sea en forma de reasignación de impuestos o de distribución obligatoria de los ingresos, reduce el control central de los ingresos y gastos agregados del sector público (Burki et al., 1999). Como destaca un documento del Ministerio de Hacienda de Colombia (2009), la participación automática de las entidades territoriales en los ingresos fiscales nacionales condenaba al fracaso cualquier esfuerzo por estabilizar las finanzas públicas, porque todo aumento tributario del gobierno central se traducía en un incremento automático del gasto territorial, muchas veces improductivo.

La mayoría de las iniciativas descentralizadoras se pusieron en marcha "a espaldas" de la política macroeconómica y sin establecer restricciones presupuestales a los GS (Aghón, 1997; Wiesner, 2003). Se crearon incentivos para que estos desatendieran sus fuentes de recursos propios y actuaran en forma macroeconómicamente "perversa". $\mathrm{E} 1$ aumento de las transferencias nacionales los indujo a reducir sus impuestos al tiempo que ampliaban sus gastos, forzando a mayores transferencias o "aprovechando" su nueva base de ingresos para respaldar un endeudamiento creciente ${ }^{20}$. La irresponsabilidad en la ejecución de los nuevos recursos dio impulso a GS con amplios déficits fiscales, que en muchos casos debieron ser rescatados financieramente por el gobierno nacional. América Latina tiene una historia de un lamentable descontrol en materia de endeudamiento territorial, más por déficits de presupuesto que por necesidades de inversión, que ha puesto en riesgo el equilibrio macroeconómico de los gobiernos centrales (Durán y Agulleiro, 2008).

E1 caso paradigmático es el argentino (Cetrángolo et al., 2002), donde el déficit consolidado de las provincias creció un $242 \%$ y el promedio de recursos de coparticipación para el pago de servicios de deuda llegó al 52\% de dichos recursos entre 1997 y 1999. En Brasil el superávit primario del gobierno central fue del 4,4\% del PIB en el periodo 1994-1998, mientras que los estados y municipios, pese a la gran descentralización tributaria, tuvieron un déficit del 1,2\% del PIB (Kopits et al., 2002). Desde hacía décadas, el financiamiento subnacional en México estaba garantizado por las transferencias del gobierno central y el sistema financiero se acostumbró a recurrir al gobierno federal cuando los gobiernos locales incumplían sus obligaciones;

${ }^{20}$ Ocampo (1995) señala que en Colombia las mayores transferencias sirvieron, sobre todo en 1994 y 1995, para apalancar el endeudamiento territorial, provocando el sobreendeudamiento de algunas entidades locales y, al final, distorsiones macroeconómicas. Este proceder atenta además contra la democracia local porque limita los planes de los gobiernos siguientes. Por tanto, hubo razones económicas y políticas para introducir correctivos legales que limitaron el sobreendeudamiento. 
este siempre las pagaba para evitar su colapso financiero (Herrera et al., 2010). La deuda subnacional garantizada con participaciones federales llegó al 45\% del PIB en 2000 (Andrade y Panti, 2004). Aun en Chile, donde la prudencia y la desconfianza se tradujeron en una amplia regulación financiera local ${ }^{21}$, muchos municipios acumularon un alto volumen de obligaciones y algunos cayeron en la insolvencia; debido a la actitud irresponsable de las autoridades locales, a problemas del sistema de responsabilidades y de financiamiento municipal, así como a un marco normativo ineficaz (de la Cruz, 2010). Así, las perturbaciones macroeconómicas no se compensaron con visibles ganancias sectoriales (en salud y educación principalmente), con un "doble costo" (Wiesner, 2003).

A pesar de los problemas mencionados, esta manera de adelantar la descentralización fiscal no se modificó durante mucho tiempo. Se adoptó sin establecer sistemas de información adecuados, sin evaluaciones independientes del proceso y sin incentivar los resultados positivos.

Cabe señalar, por último, que no todo fue negativo en el inicio del proceso. Como todo proceso macrosocial tuvo retos y desafíos que se debían enfrentar. Aghón (1997) señala un aspecto positivo: la multiplicación de experiencias y procesos de gestión y de política pública, que alentó el espíritu innovador de algunos GS "exitosos", que con su nueva autonomía desarrollaron "mejores prácticas” en áreas como la distribución de responsabilidades, el esfuerzo fiscal y la modernización de sus sistemas tributarios, la provisión de servicios sociales, esquemas novedosos de participación comunitaria y, en general, en campos de experimentación que ampliaron las opciones para resolver problemas específicos de la administración descentralizada ${ }^{22}$.

\section{REFORMAS DE SEGUNDA GENERACIÓN}

A medida que los inconvenientes se hacían evidentes y los resultados anunciados brillaban por su ausencia el modelo descentralizador empezó a cambiar, así como la postura que hasta entonces tenían las autoridades nacionales. A finales de los noventa los gobiernos centrales adoptaron una actitud más cautelosa hacia las reformas, impusieron

21 Desde 1990 se han aprobado tres reformas de las normas constitucionales sobre administración territorial; tan solo entre 2000 y 2005 se aprobaron 23 leyes (Subdere, 2006).

22 Rosales y Valencia (2008) destacan algunos gobiernos locales de gestión paradigmática: Curitiba y Porto Alegre en Brasil; Villa El Salvador en Perú; Bogotá en Colombia; Cotacachi y Guayaquil en Ecuador; Santiago de Chile; Mérida, San Pedro Garza y San Nicolás de los Garza en México; Rafaela en Argentina; y La Paz en Bolivia. 
marcos regulatorios más estrictos a las finanzas intergubernamentales y sistemas de seguimiento y evaluación del desempeño fiscal de los entes subnacionales. Se requería una "estrategia comprehensiva" que tuviese en cuenta variables políticas, fiscales, institucionales y organizacionales del sector público. Hay elementos que no pueden faltar en una estrategia de descentralización coherente (de la Cruz, 2010): reglas fiscales para controlar los déficits, la contratación de deuda y la calidad del gasto subnacional, la coordinación de inversiones, el fortalecimiento institucional y gerencial, etc. Como dice Campbell (2010), los países se apresuraron a formular elementos puntuales de carácter jurídico-político, en vez de trazar una estrategia que incluyera el desarrollo económico, el fortalecimiento institucional y el financiamiento adecuado.

E1 nuevo enfoque se vio favorecido por un renovado marco conceptual que se añadió a la justificación teórica clásica (Tiebout, 1956; Oates, 1977), y que llevó al primer plano el tema de la eficiencia. Este enfoque, de segunda generación (Weingast, 1995; Qian y Weingast, 1997), reconoce que los agentes públicos toman decisiones con información parcial y asimétrica, y buscan lograr sus intereses en el contexto político en que actúan. Propone entonces una serie de condiciones que se deben cumplir en su totalidad para que la descentralización fiscal sea eficiente, promoviendo la competencia, es decir, los mecanismos de mercado: jerarquía vertical estricta, autonomía subnacional efectiva, régimen de mercado común, fuertes restricciones presupuestales y autoridad subnacional institucionalizada.

Conforme a estas condiciones y en un esfuerzo por crear incentivos adecuados, controlar las finanzas subnacionales y lograr la sostenibilidad fiscal, muchos países diseñaron una segunda generación de reformas que, en general, consisten en replantear las prioridades del proceso. De acuerdo con Restrepo (2004), las nuevas prioridades buscaban atender preocupaciones hasta entonces ignoradas: lograr unas finanzas locales sanas con endeudamiento moderado, estimular el esfuerzo tributario local, promover incentivos y mecanismos de mercado, y justificar el número y la creación de los niveles administrativos. Según este autor, se adoptó una óptica más compleja y sofisticada, que superaba el enfoque cuantitativo de transferencia de recursos y competencias, para mejorar la eficiencia de los servicios públicos, la participación ciudadana y los mecanismos de coordinación entre finanzas públicas locales y nacionales ${ }^{23}$.

${ }^{23}$ Como indica Fleury (1999), la segunda generación de reformas estructurales (entre las que se cuentan las reformas descentralizadoras) surgió después de constatar el fracaso de las reformas de primera generación, que no sentaron las 
Esta nueva óptica dio lugar a una actitud más conservadora que tenía en cuenta de modo más explícito los riesgos asociados y los incentivos requeridos. Como se observa en la gráfica 2, esta nueva generación de reformas puso fin a la expansión de los GS a comienzos de siglo, y su participación se estabilizó alrededor del 21\% del total de ingresos del gobierno general ${ }^{24}$ (un $38 \%$, ponderado por el tamaño absoluto de los sectores públicos). E1 debate se centró en cuatro áreas: la excesiva dependencia de las transferencias del gobierno central, los incentivos de los gobiernos locales para sobreendeudarse, los problemas de recursos comunes debidos a la deficiente distribución de funciones y fuentes financieras, y la baja capacidad institucional de la mayoría de esos gobiernos.

\section{Gráfica 2}

Ingreso público subcentral como porcentaje del ingreso público total,19902009

(Promedio ponderado de 17 países)

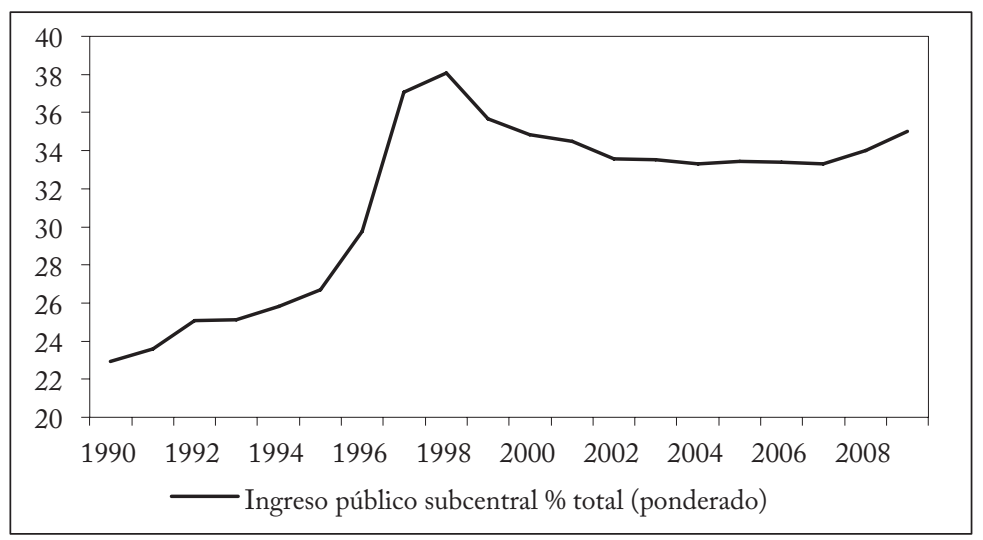

Nota: promedio de las cifras anuales.

Fuentes: Cepal (2007, 2010); World Bank (2001) para la mayoría de los países y años; Banco del Estado del Ecuador (2009); Eguino et al. (2002); World Bank (2012); Vargas (2013); FMI (2004); Contraloría General de la República de Panamá (2009); Michelin (1999); BID (2009); Mascareño (2000); CepalsTAT y otras fuentes nacionales.

Los gobiernos hicieron esfuerzos para revertir los efectos perversos del proceso descentralizador. El primero fue establecer un marco regulador más claro y amplio, cuya ausencia llevó a establecer restricciones

bases para un desarrollo sostenible ni redujeron en forma significativa la pobreza y la desigualdad. Se inspiraron en el neoinstitucionalismo y en la teoría de la elección pública basada en el principal-agente.

${ }_{24} I P S B=\frac{I P L+I P E}{I P L+I P E+I P C}$, donde IPSB $=$ ingreso público subcentral como porcentaje del total; IPL $\stackrel{I P L+I P E+I P C}{=}$ ingreso público local; IPE = ingreso público estatal (nivel medio), e IPC = ingreso del gobierno central. 
presupuestales blandas; reglas fiscales y procesos presupuestales más jerárquicos y transparentes que limitarían los déficits primarios (Filc y Scartascini, 2004). El segundo fue desarrollar mecanismos de información, seguimiento y control de la gestión fiscal de los GS, en especial del endeudamiento y del uso de las transferencias. Esos sistemas debían, por ejemplo, desligar las transferencias del recaudo de impuestos nacionales, y ligarlas a otros criterios, como la equidad interregional, la eficiencia y el esfuerzo fiscal, la prestación descentralizada de servicios, etc.

Estos esfuerzos mostraron que el énfasis en la descentralización política se trasladó a la eficiencia del gasto público. Si las transferencias eran el principal instrumento fiscal de la descentralización, la cuestión es si estas impulsan a los GS a tomar decisiones de gasto acordes con sus ingresos propios (Finot, 2005). Un sistema en el que las transferencias son proporcionales a los aportes locales mejora la eficiencia y la equidad territorial. Entre los mecanismos ideados para que los GS obtuvieran más recursos propios y mejoraran la gestión de los que se les transferían se recurrió a premiar con mayores transferencias a los que aumentaran su recaudo o a limitar las transferencias mediante "embudos fiscales" (sistemas nacionales de inversión o de acreditación) que retrasaban o dificultaban el flujo de recursos a los GS (de la Cruz, 2010). Parecía que para garantizar la prestación eficiente y equitativa de los servicios públicos bastaba establecer mandatos y reglamentos para los GS y las transferencias que combinaran incentivos y restricciones. De modo que se requerían asignaciones financieras bien definidas, sistemas de información que dieran informes oportunos del desempeño de sus finanzas y su producción, y mecanismos de revisión sistemática para sancionar casos de bajo rendimiento o recompensar rendimientos excepcionales (Winkler, 1994).

Pero una mayor y mejor regulación fiscal, mejores sistemas de información y evaluación, y sistemas de transferencias más complejos son pasos positivos pero insuficientes, pues no llegan a la raíz del problema: la autonomía fiscal real de las entidades locales. Los esfuerzos para establecer sistemas de información y reformar los sistemas de transferencias deben coincidir con la ampliación de las potestades tributarias de los GS, para que las comunidades territoriales puedan determinar, a través de procesos democráticos, el nivel de impuestos que contribuya a financiar el gasto que decidan. Una solución es aumentar las competencias tributarias, modernizar y simplificar los tributos locales, ampliar los ingresos no tributarios, y asignar más recursos al ámbito local mediante contribuciones de mejoras y concesiones (Aghón, 1999). 
Algunos autores señalan en forma expresa que la descentralización efectiva requiere que los GS tengan autonomía para obtener recursos tributarios propios y asignarlos según las demandas de sus comunidades (Lora y Cárdenas, 2006; Daughters y Harper, 2007). Pero el interés por fortalecer los sistemas tributarios locales no se ha concretado en medidas ciertas, como ampliar las bases gravables locales y explotarlas en forma más efectiva. La asignación de impuestos poco ha cambiado en los últimos años, quizá debido al bajo número de impuestos adecuados al ámbito local, ya que deben cumplir los siguientes requisitos: simpleza en su administración, evitar la competencia tributaria entre GS y demostrar una asociación directa con los beneficios que financian. Los ejemplos más comunes son los impuestos a la propiedad, a los vehículos y a la venta de inmuebles, las tarifas de agua potable y las tasas a la industria y el comercio. Puesto que estos impuestos tienen bajo potencial para generar ingresos, los GS no pueden recaudar, mediante fuentes propias, los recursos necesarios para cubrir sus gastos, lo que obliga al gobierno nacional a completar sus recursos con transferencias. Además, existen otras circunstancias que se oponen al fortalecimiento tributario local: la resistencia de las autoridades centrales a otorgar facultades tributarias significativas a los GS, el temor a la competencia tributaria, la baja capacidad para administrar impuestos y la posible ampliación de las desigualdades regionales. Con respecto a esto último, cabe destacar que en América Latina es usual que una o dos regiones concentren gran parte de la población y de la actividad económica, y que tengan más capacidad para generar ingresos tributarios, en perjuicio de otras jurisdicciones. La brecha entre jurisdicciones ricas y pobres es muy grande, y la capacidad para generar ingresos propios vía impuestos tiende a reforzar las desigualdades entre regiones de mayor y menor capacidad de recaudo (Gómez y Jiménez, 2011).

Entre los países de mayor autoridad tributaria local -Argentina, Brasil y Colombia - cabe destacar el caso de Brasil, donde la Constitución de 1988 fortaleció notablemente la autoridad tributaria subnacional, y es el único país de América Latina que tiene un IVA subnacional. En Chile, que ha realizado un proceso de municipalización, la participación tributaria subnacional pasó del 7,2\% del ingreso total en 1990 al 8,6\% en 2000. En Centroamérica siguen existiendo grandes diferencias entre obligaciones de gasto y fuentes tributarias locales; E1 Salvador fijó impuestos a la nómina a nivel local; en Guatemala se promovieron leyes para modernizar los impuestos municipales; y en Nicaragua se expidió la Ley de Solvencia Municipal (2003), que auto- 
rizó a los municipios a gravar los activos fijos y las ventas. En México los gobiernos locales tienen una historia de excesiva dependencia de las transferencias federales; solo el 10\% (en promedio) de los ingresos de los estados provenía de ingresos propios; el principal impuesto municipal (a la propiedad) solo recaudó el 0,2\% del PIB en 2006 (mientras que Colombia, Argentina y Brasil recaudaban más del 1,2\%); apenas en 2007, por medio de una importante reforma tributaria, se dotó a los GS de la capacidad para administrar impuestos con alto potencial de recaudo, como el impuesto especial sobre producción y servicios (IEPS) (a la gasolina, p. ej.) y sobre vehículos (González, 2010).

Otro aspecto importante de esta segunda oleada de reformas fue la capacidad de endeudamiento de los entes locales, cuando se hizo evidente la necesidad de reglas de endeudamiento rígidas para limitar el gasto de los gobiernos locales. La falta de restricciones fue una de las principales causas de los problemas fiscales de Brasil y Colombia en los noventa, y los obligó a adoptar medidas para controlar su endeudamiento. Después las adoptaron Ecuador, Bolivia, México y Perú. Lora y Cárdenas (2006) y Daughters y Harper (2007) identifican cuatro tipos de restricciones: prohibición total de endeudarse (solo en Chile), endeudamiento condicionado a la aprobación del gobierno central, limitación del uso de los fondos (normalmente para gastos de inversión) y límites cuantitativos.

Brasil fue pionero en la adopción de controles al endeudamiento subnacional; en 1995 creó un sistema que recogía información detallada de la situación financiera de los entes territoriales, y elaboró un plan de reducción de pasivos que se inició en ese año con la creación del CADIN ${ }^{25}$, que obligó a los GS a presentar información financiera detallada al Gobierno Federal cuando su deuda estuviera atrasada. En 1997 creó el PROES (Programa de incentivos para la reducción del sector público estatal en la actividad bancaria), para manejar las obligaciones financieras de los gobiernos estatales debido a la frecuente insolvencia de los bancos estatales, y el programa para el apoyo financiero y renegociación de la deuda de los gobiernos estatales, que redefinió las reglas y mecanismos de endeudamiento de los estados, y fortaleció el uso de medidas estándar para evaluar su desempeño fiscal $^{26}$. Las reformas iniciales se reunieron bajo el paraguas de la

${ }^{25}$ Cadastro informativo de créditos não quitados do Setor Público Federal (lista de créditos vencidos con el Sector Público Federal), una base de datos de deudores con las entidades federales que permite estandarizar los procedimientos para otorgar créditos, garantías, incentivos fiscales y financieros, celebrar acuerdos y gestionar los recursos.

${ }^{26}$ Esta evaluación es uno de los puntos más importantes de la segunda oleada de reformas. Por ejemplo, en Colombia se estableció por ley la obligación de 
Ley de Responsabilidad Fiscal Integral aprobada en 2000. Esta ley, sin precedentes en la región, estableció un nuevo régimen fiscal de largo alcance para todos los niveles de gobierno (en particular los GS), precisó y consolidó las reglas de endeudamiento (incluida la prohibición de endeudamiento intergubernamental) y fijó estándares de eficiencia fiscal. Esta ley reflejó dos avances importantes. Primero, el reconocimiento de que sin reglas fiscales "correctas" es imposible que la nación en su conjunto cumpla los distintos objetivos de equidad y política económica. Segundo, el consenso político de que es necesario cumplir preceptos macroeconómicos técnicos y ortodoxos (Wiesner, 2003).

Colombia también estableció en 1997 un sistema de seguimiento del comportamiento fiscal local y diversas condiciones para habilitar el endeudamiento, conocidas como Ley de Semáforos ${ }^{27}$, mediante las cuales se evaluaba la situación crediticia de los GS y se condicionaban los préstamos según la señal (luz roja, amarilla o verde) a mayores o menores restricciones o permisos del gobierno central. Después se aprobaron otras leyes que reestructuraron sus deudas y establecieron un sistema de indicadores para regular el gasto subnacional con el fin de generar superávits fiscales. Se tomaron otras medidas, como la prohibición de que las transferencias para salud y educación se incluyeran en el cálculo de su capacidad de endeudamiento y la obligación de obtener calificaciones de riesgo para obtener crédito. El proceso se consolidó en 2003 con la sanción de la Ley de Responsabilidad Fiscal. Ecuador y Perú también aprobaron leyes de responsabilidad fiscal que regulan el endeudamiento subnacional. En México, dadas las garantías constitucionales del Estado federal, que protegen la autonomía de los entes territoriales, se recurrió a una "regulación indirecta" que no fijó restricciones de endeudamiento a los estados o municipios sino a las entidades de crédito. El objetivo era ponderar los riesgos del crédito subnacional sin afectar su fluidez, mediante la calificación de al menos dos calificadoras autorizadas. Los GS se mostraron cada

hacer anualmente esta evaluación; y se elaboró una metodología para determinar el desempeño fiscal a partir de componentes tales como solvencia para mantener el funcionamiento, cumplimiento de los límites de gasto, nivel de recursos propios (solvencia tributaria), nivel de inversión, respaldo adecuado de la deuda, generación de ahorro corriente, etc.

${ }^{27}$ La Ley 795 de 2003 solo dejó dos señales (verde y roja), construidas conforme a las siguientes relaciones entre intereses de la deuda (ID), saldo de la deuda (SD), ingresos corrientes (IC) y ahorro operacional (AO, diferencia entre ingresos corrientes y gastos de funcionamiento): si $\mathrm{ID} / \mathrm{AO}<40 \%$ y $\mathrm{SD} / \mathrm{IC}<80 \%$, el nivel de endeudamiento es seguro y la entidad tiene plena autonomía para endeudarse (luz verde). Si los indicadores superan esos límites, se requiere autorización del Ministerio de Hacienda para contratar nueva deuda. 
vez más dispuestos a solicitar la calificación (Herrera et al., 2010); y en 2000 se creó un sistema novedoso basado en señales de mercado, divulgación de información fiscal de los gobiernos y regulación a las entidades financieras para las operaciones con GS.

\section{CONCLUSIONES}

Aunque hay grandes diferencias en el proceso de descentralización de América Latina, se detectan algunas características comunes. La descentralización se inició por razones políticas que explican la configuración de las instituciones fiscales. Se impuso la idea de que esta era un objetivo en sí misma, más que un medio para mejorar la eficiencia de la gestión pública. La "descentralización a cualquier precio" llevó a establecer sistemas de transferencias amplios y automáticos del gobierno nacional a los GS, sin mayores condiciones. En esta etapa, unos defendieron la descentralización como un modo de profundizar la democracia y otros como una manera de fomentar la competencia y la libertad de mercado, y fue apoyada por todo el espectro político.

E1 traslado forzoso de enormes recursos, sin transferir potestades tributarias, agravó los desequilibrios macroeconómicos pues los GS adoptaron un perfil ejecutor (con baja capacidad administrativa y poca participación ciudadana) en detrimento de su papel recaudador. Esto desincentivó la ejecución responsable de los recursos y produjo grandes déficits fiscales. Por otra parte, la descentralización no satisfacía las grandes expectativas sociales que la justificaron. Pero poco a poco surgió un aprendizaje institucional, a nivel central y subnacional, que ha permitido completar el proceso y establecer incentivos adecuados para contrarrestar su impacto negativo. Y hoy es claro que la descentralización fiscal exige un nivel de institucionalización mínimo, marcos regulatorios y fiscales que mejoren la capacidad administrativa y fiscal de los GS (sobre todo su capacidad tributaria), su autonomía y su responsabilidad. Y, además, una ciudadanía más informada y participativa.

La descentralización fiscal puede ser un proceso sin retorno y llevar a un mayor desarrollo institucional. Habrá de continuar promoviendo la autonomía financiera local con ingresos propios adecuados, mayores competencias tributarias y un recaudo más eficiente. Para que así ocurra, los gobiernos y sociedades locales habrán de tener más protagonismo. 


\section{ANEXO}

\section{FUENTES Y METODOLOGÍA DEL INDICADOR DE DESCENTRALIZACIÓN FISCAL}

En las dos últimas décadas hubo una descentralización fiscal creciente que se tradujo en una mayor participación del gasto y del ingreso local en el gasto y el ingreso nacional, o en el PIB de la región. No obstante, hay fuertes diferencias en el nivel de autonomía local para gestionar el ingreso fiscal y el gasto. La evolución del tamaño del sector público local en los distintos países es un buen indicador del desarrollo y la profundidad del proceso descentralizador. En los últimos años se han hecho numerosos esfuerzos para entender mejor la descentralización fiscal y el sector público local en América Latina, algunos de ellos centrados en los aspectos fiscales, relativamente fáciles de cuantificar.

\section{Cuadro 1}

Fuentes para construir el panel, América Latina (17 países)

\begin{tabular}{|c|c|c|}
\hline País & Fuentes principales & \multirow{7}{*}{$\begin{array}{l}\text { Fuentes secundarias } \\
\text { WB (2012), Gómez y Jiménez (2011) } \\
\text { WB (2012), FMI (2004), Gómez y Jiménez } \\
\text { (2011) } \\
\text { WB (2012), Gómez y Jiménez (2011) } \\
\text { Mejía y Atanasio (2008), Durán y Agulleiro } \\
\text { (2008), DIPRES (2000, 2009, 2011), Gómez y } \\
\text { Jiménez (2011) } \\
\text { Dillinger y Webb (1999), FMI (2005), Zapata } \\
\text { (2010), Gómez y Jiménez (2011), Banco de la } \\
\text { República (2010) } \\
\text { Gómez y Jiménez (2011), Espitia (2004), Eguino } \\
\text { et al. (2002) }\end{array}$} \\
\hline Argentina & Cepal $(2007,2010), \mathrm{WB}(2001)$ & \\
\hline Bolivia & Cepal $(2007,2010)$, WB (2001) & \\
\hline Brasil & Cepal $(2007,2010), \mathrm{WB}(2001)$ & \\
\hline Chile & Cepal $(2007,2010)$, WB (2001) & \\
\hline Colombia & Cepal $(2007,2010)$, WB (2001) & \\
\hline Costa Rica & Cepal $(2007,2010)$, WB (2001) & \\
\hline Ecuador & $\begin{array}{l}\text { Cepal (2007, 2010), Banco del Estado } \\
\text { (2009). }\end{array}$ & Gómez y Jiménez (2011) \\
\hline E1 Salvador & Eguino et al. (2002), WB (2012) & \multirow{5}{*}{$\begin{array}{l}\text { Espitia (2004) } \\
\text { Espitia (2004), ICMA (2004), FMI (2004) } \\
\text { Espitia (2004), WB (2012) } \\
\text { Durán y Agulleiro (2008), OECD (2013). } \\
\text { WB (2001, 2012), Espitia (2004), Eguino et al. } \\
(2002)\end{array}$} \\
\hline Guatemala & WB (2001), Eguino et al. (2002) & \\
\hline Honduras & Eguino et al. (2002), Vargas (2013) & \\
\hline México & Cepal $(2007,2010)$, WB (2001) & \\
\hline Nicaragua & FMI (2004) & \\
\hline Panamá & $\begin{array}{l}\text { WB (2001), Contraloría General de la } \\
\text { República (2009) }\end{array}$ & Eguino et al. (2002), Espitia (2004), FMI (2004) \\
\hline Paraguay & Cepal $(2007,2010)$, WB (2001) & \multirow{3}{*}{$\begin{array}{l}\text { Neffa (2001) } \\
\text { Durán y Agulleiro (2008), Gómez y Jiménez } \\
\text { (2011), Canavire et al. (2012) }\end{array}$} \\
\hline Perú & Cepal $(2007,2010)$, WB (2001) & \\
\hline $\begin{array}{l}\text { Uruguay } \\
\text { Venezuela }\end{array}$ & $\begin{array}{l}\text { Michelin (1999), BID (2009) } \\
\text { Mascareño (2000) }\end{array}$ & \\
\hline
\end{tabular}

Fuente: elaboración propia.

Por ello, una vez construido el indicador, se consultó el mayor número de fuentes para comprobar la confiabilidad de los datos y construir series de todo el periodo, 1990-2009. Además, se tuvieron en cuenta la coincidencia, exacta o próxima, de los datos, y el rigor de la fuente. Se trató de abarcar el mayor número de países y de años, y que los datos fueran lo más homogéneos posible, para determinar la tendencia del periodo y hacer comparaciones entre países. La principal fuente de los datos utilizados fue la Cepal. Su Estudio económico de América Latina y el Caribe anual y su anexo estadístico 
"Indicadores fiscales de los gobiernos subnacionales" aportan datos de 1996 a 2009 para 10 países de la muestra. Las cifras se completaron con datos de indicadores de descentralización fiscal del Banco Mundial, que se basan en las estadísticas de finanzas públicas del FMI y en fuentes nacionales. Para los otros siete países de la muestra (E1 Salvador, Guatemala, Honduras, Nicaragua, Panamá, Uruguay y Venezuela) se recurrió a estudios y fuentes nacionales o regionales.

E1 resultado es un panel no balanceado del ingreso público subcentral total como porcentaje del $\mathrm{PIB}^{28}$, de 17 países para la mayoría de los años comprendidos entre 1990 y 2009. E1 cuadro 1 resume las fuentes.

\section{REFERENCIAS BIBLIOGRÁFÍCAS}

1. Aghón, G. "Fortalecimiento de las finanzas municipales, dificultades y nuevos desafíos para los países de la región", G. Aghón y H. Edling, comps., Descentralización fiscal en América Latina, nuevos desafíos y agenda de trabajo, Santiago de Chile, Cepal-GTZ, 1997.

2. Aghón, G. "Descentralización fiscal, tendencias y tareas pendientes", Serie de estudios de economía y ciudad 3, Bogotá, Alcaldía Mayor de Bogotá, 1999.

3. Ahmad, E., y M. García-E. "Economía política de la descentralización y gobernabilidad", R. de la Cruz, C. Pineda y C. Pöschl, eds., La alternativa local. Descentralización y desarrollo económico, Banco Interamericano de Desarrollo, 2010.

4. Alesina, A.; E. Spolaore y R. Wacziarg. "Economic integration and political disintegration", American Economic Review 90, 5, 2000, pp. 1276-1296.

5. Andrade, M. y H. Panti. Calificación crediticia a gobiernos subnacionales de México, Fitch Ratings, presentación al Banco Mundial, México D.F., 2004.

6. Artana, D. “Are Latin-American countries decentralized?”, documento de trabajo 92, FIEL, Buenos Aires, 2007.

7. Arzaghi, M. y J. V. Henderson. "Why countries are fiscally decentralizing", Journal of Public Economics 89, 2005, 2005, pp. 1157-1189.

8. Assies, W. "La descentralización en perspectiva", W. Assies, ed., Gobiernos locales y reforma del Estado en América Latina, México, E1 Colegio de Michoacán, 2003.

9. Banco de la República de Colombia. Balance fiscal - Consolidado entidades territoriales, Bogotá, 2010.

10. Banco del Estado de la República del Ecuador. Las finanzas subnacionales en el Ecuador 1993-2008, Quito, 2009.

11. Bardhan, P. "Decentralization of governance and development", Journal of Economic Perspectives 16, 4, 2002, pp. 185-205.

${ }^{28}$ También se puede obtener así el ingreso público subcentral como porcentaje del ingreso público total: $\operatorname{IPSB}_{\mathrm{it}}=\left(\mathrm{IPL}_{\mathrm{it}}+\mathrm{IPE}_{\mathrm{it}}\right) /\left(\mathrm{IPL}_{\mathrm{it}}+\mathrm{IPE}_{\mathrm{it}}+\mathrm{IPC}_{\mathrm{it}}\right)$, donde IPSB = ingreso público subcentral como porcentaje del total; IPL = ingreso público local, IPE = ingreso público estatal (nivel medio) e y IPC = ingreso público del gobierno central. 
12. Bervejillo, F. “Gobierno local en América Latina. Casos de Argentina, Chile, Brasil y Uruguay”, D. Nohlen, ed., Descentralización politica $y$ consolidación democrática. Europa-América del Sur, Caracas, Nueva Sociedad, 1991.

13. BID. Finanzas y gestión de los gobiernos subnacionales en Uruguay, nota técnica UR-N1029, Washington, 2009.

14. Burki, S. J.; G. Perry y W. R. Dillinger. Beyond the center, decentralizing the State, Washington, D. C., World Bank, 1999.

15. Cabrero, E. "Los retos institucionales de la descentralización fiscal en América Latina”, Reforma y Democracia 34, 2006, p. 1-19.

16. Campbell, T. The quiet revolution, decentralization and the rise of political participation in Latin American Cities, Pittsburgh, University of Pittsburgh Press, 2003.

17. Campbell, T. “Condiciones para el desarrollo económico y social en los sistemas de gobierno descentralizado", R. de la Cruz, C. Pineda y C. Pöschl, eds., La alternativa local. Descentralización y desarrollo económico, Washington, BID, 2010.

18. Canavire-B., G.; J. Martínez-V. y C. Sepúlveda. "Sub-national revenue mobilization in Peru”, working paper series IDB-WP-299, 2012.

19. Castro, J. "Descentralización en Colombia y la transformación de Bogotá”, R. de la Cruz, C. Pineda, y C. Pöschl, eds., La alternativa local. Descentralización y desarrollo económico, Washington, BID, 2010.

20. Cepal. Estudio económico de América Latina y el Caribe 2006-2007, Santiago de Chile, Cepal, 2007.

21. Cepal. Estudio económico de América Latina y el Caribe 2009-2010. Impacto distributivo de las políticas públicas, Santiago de Chile, Cepal, 2010.

22. Cetrángolo, O.; J. P. Jiménez et al. "Las finanzas públicas provinciales, situación actual y perspectivas", Serie estudios y perspectivas 12, Cepal, Buenos Aires, 2002.

23. Contraloría General de la República de Panamá. Total de ingresos y gastos de los municipios de la República: años 2001-10, Panamá, 2009.

24. Daughters, R. y Harper, L. "Reformas de descentralización fiscal y política”, E. Lora, ed., El estado de las reformas del Estado en América, Washington, D. C., IADB, 2007.

25. De la Cruz, R. "Descentralización y desarrollo local en América Latina”, R. de la Cruz, C. Pineda y C. Pöschl, eds., La alternativa local. Descentralización y desarrollo económico, BID, 2010.

26. Dillinger, W. y S. B. Webb. Decentralization and fiscal management in Colombia, World Bank, 1999.

27. DIPRES. "Estadísticas de las finanzas públicas 1990-1999”, Santiago, Ministerio de Hacienda, Chile, 2000.

28. DIPRES. "Estadísticas de las finanzas públicas 1999-2008”, Santiago, Ministerio de Hacienda, Chile, 2009.

29. DIPRES. "Estadísticas de las finanzas públicas 2001-2010”, Santiago, Ministerio de Hacienda, Chile, 2011.

30. Durán, V. y N. Agulleiro. La descentralización del ingreso fiscal en América Latina, documento 29/08, Madrid, Instituto de Estudios Fiscales, 2008. 
31. Ebel, R. y S. Yilmaz. "On the measurement and impact of fiscal decentralization", J. Martínez y J. Alm, eds., Public finance in developing and transitional countries, Essays in honor of Richard Bird, Cheltenham, Elgar, 2003.

32. Eguino, H.; J. A. Pérez et al. "Ingresos municipales en Centroamérica, situación actual y perspectivas de modernización”, Memorias de la IX reunión de la Red Centroamericana por la Descentralización y Fortalecimiento Municipal, Antigua, diciembre de 2002.

33. Espitia, G. Descentralización fiscal en Centroamérica. Un estudio comparativo, San Salvador, Confedelca y GTZ, 2004.

34. Falleti, T. G. "A Sequential theory of decentralization, Latin American cases in comparative perspective”, American Political Science Review 99, 3, 2005, pp. 327-346.

35. Filc, G. y C. Scartascini. Budget institutions and fiscal outcomes. Ten years of inquiry on fiscal matters at the research department, Paper prepared for the Research Department $10^{\text {th }}$ Year Anniversary Conference, Washington D. C., BID, 2004.

36. Finot, I. "Descentralización del Estado y participación ciudadana en América Latina. Un enfoque crítico", documento LC/IP/R.206, Santiago de Chile, Cepal, 1998.

37. Finot, I. "Descentralización en América Latina, teoría y práctica", Santiago de Chile, ILPES, Cepal, 2001.

38. Finot, I. "Descentralización, transferencias territoriales y desarrollo local”, Revista de la Cepal 86, 2005, pp. 29-46.

39. Fleury, S. "Reforma del Estado en América Latina, ¿hacia dónde?", Nueva Sociedad 160, 1999, pp. 58-80.

40. FMI. Nicaragua. Country Report n. ${ }^{\circ}$ 04/347, Washington, D. C, 2004.

41. Franco, R. "Descentralización, participación y competencia en la gestión social”, R. Gomà y J. Jordana, eds., Descentralización y politicas sociales en América Latina, Fundació CIDOB, Barcelona, 2004, pp. 29-40.

42. Gómez S., J. C. y J. P. Jiménez. "E1 financiamiento de los gobiernos subnacionales en América Latina: un análisis de casos", Serie macroeconomía del desarrollo 111, Santiago de Chile, Cepal y GIZ, 2011.

43. González A., J. A. "Reforma del federalismo fiscal en México", R. de la Cruz, C. Pineda y C. Pöschl, eds., La alternativa local. Descentralización y desarrollo económico, BID, 2010.

44. Herrera, V. M.; D, Brandazza y F. Ortiz. "Calificación de riesgo crediticio de entidades subnacionales", R. de la Cruz, C. Pineda y C. Pöschl, eds., La alternativa local. Descentralización y desarrollo económico, BID, 2010.

45. ICMA. "Informe de país, E1 Salvador. Tendencias en la descentralización, el fortalecimiento municipal y la participación ciudadana en América Central, 1995-2003”, AID-ICMA, 2004.

46. Kopits, G.; J. P. Jiménez y A. Manoel. "Responsabilidad fiscal a nivel subnacional, Argentina y Brasil”, Trimestre Fiscal 73, 2002, pp. 199-234.

47. Letelier S., L. "Explaining fiscal decentralization", Public Finance Review 33, 2, 2005, pp. 155-183. 
48. Lora, E. y M. Cárdenas. "La reforma de las instituciones fiscales en América Latina”, documento de trabajo 559, Washington, D.C., Fedesarrollo y BID, 2006.

49. Mascareño, C., coord. Balance de la descentralización en Venezuela: logros, limitaciones y perspectivas, Caracas, Nueva Sociedad, 2000.

50. Mascareño, C. "Descentralización y democracia en América Latina, ¿una relación directa? Revisión conceptual del estado del arte”, $R e-$ forma y Democracia 45, 2009, pp. 63-98.

51. Mejía, C. y O. Atanasio. "Descentralización en América Latina. Estudios de caso”, documento 30/08, Madrid, Instituto de Estudios Fiscales 2008.

52. Michelín, G. "Finanzas de los gobiernos departamentales en Uruguay", Estudios 9, CERES, 1999.

53. Ministerio de Hacienda y Crédito Público, Colombia. Diez años de transformación fiscal territorial en Colombia 1998-2008, Bogotá D. C., 2009.

54. Musgrave, R. y P. Musgrave. Hacienda pública. Teórica y aplicada, 5. ${ }^{\mathrm{a}}$ ed., Madrid, McGraw Hill, 1992.

55. Neffa, J. A. "Descentralización fiscal: el caso paraguayo”, Serie política fiscal 91, Cepal y GIZ, 2001.

56. Nickson, A. Local government in Latin America, Boulder, Co., Lynne Rienner Publishers, 1995.

57. Nickson, A. "Tendencias actuales de las finanzas locales en América Latina", Reforma y Democracia 12, 1998, pp. 71-88.

58. Nickson, A. "La descentralización política", I. Crespo y A. Martínez, eds., Politica y gobierno en América Latina, Valencia, Tirant lo Blanch, 2005, pp. 169-202.

59. Oates, W. E. Federalismo fiscal [1972], Madrid, Instituto de Estudios de Administración Local, 1977.

60. Ocampo, J. A. “E1 proceso colombiano de descentralización”, ponencia inaugural en el seminario internacional sobre descentralización fiscal en América Latina, Mejores prácticas y lecciones de política, Cartagena de Indias, Cepal, 1995.

61. OECD, Fiscal Decentralisation Database. "Revenue and spending shares of state and local government", 2013.

62. Oxhorn, P. "Introduction: Unraveling the puzzle of decentralization", P. Oxhorn, J. S. Tulchin y A. D. Selee, eds., Decentralization, civil society, and democratic governance: Comparative perspectives from Latin America, Africa, and Asia, Washington, D. C., 2004.

63. Panizza, U. "On the determinants of fiscal centralization: Theory and evidence", Journal of Public Economics 74, 1, 1999, pp. 97-139.

64. Penfold, M. "Descentralización y mercado en América Latina”, Reforma y Democracia 16, 2000.

65. Qian, Y. Y. y B. R. Weingast. "Federalism as a commitment to preserving market incentives", Journal of Economic Perspectives 11, 4, 1997, pp. 83-92.

66. Restrepo S., J. "La segunda generación de las reformas descentralistas en América Latina”, ponencia presentada en la Conferencia Anual de 
Ejecutivos Competitividad y Desarrollo en la Democracia, Panamá, marzo de 2004.

67. Restrepo, D. "Historias comparadas. Las fracturas del Estado en América Latina”, D. Restrepo, coord. Historias de la descentralización. Transformaciones del régimen politico y cambio en el modelo económico. América Latina, Europa y EUA, Bogotá, Universidad Nacional de Colombia, 2006, pp. 25-52.

68. Ríos, G.; F. Ortega y J. S. Scrofina. "Sub-national revenue mobilization in Latin America and Caribbean Countries: The case of Venezuela", BID, Working paper series 300, 2012.

69. Rojas, F., "La descentralización fiscal en América latina”, Reforma y Democracia 3, 1995, pp. 7-46.

70. Rojas, F. "LAC Regional study on decentralization”, documento de respaldo para el World Development Report 1999/2000, Washington, D.C., septiembre de 1998.

71. Rojas, F. “The political context of decentralization in Latin American. Accounting for the particular demands of decentralization in the region", S. J. Burki y G. Perry, eds., Annual World Bank Conference on Development in Latin America and the Caribbean, Washington, D. C., World Bank, 1999.

72. Rosales, M. y S. Valencia. “América Latina”. Ciudades y Gobiernos Locales Unidos, eds., La descentralización y la democracia local en el mundo. Primer informe mundial de Ciudades y Gobiernos Locales Unidos, Barcelona, 2008.

73. Subsecretaría de Desarrollo Regional y Administrativo. Memoria de la Descentralización 2000-2006, SUBDERE, 2006, [http://www.subdere. gov.cl/1510/article-69387.html].

74. Tiebout, C. "Una teoría pura del gasto público local” [1956], Hacienda Pública Española 5, 1978, pp. 324- 331.

75. Touraine, A, América Latina. Politica y sociedad, Madrid, EspasaCalpe, 1989.

76. Uprimny, R. “The recent transformation of constitutional law in Latin America, trends and challenges", Texas Law Review 89, 7, 2011, pp. 1587-1609.

77. Vargas, C. Descentralización en Honduras. De un enfoque de reparto a un enfoque de desarrollo, Secretaría del Interior y Población, República de Honduras, 2013.

78. Victory, C. "Gobiernos municipales y desarrollo local en Iberoamérica", Revista CIDOB d'afers internacionals 47, 1999, pp. 15-49.

79. Weingast, B. R. "The economic role of political institutions, marketpreserving federalism and economic development", Journal of Law, Economics, and Organization 20, 1, 1995, pp. 1-31.

80. Wiesner, E. Colombia, descentralización y federalismo fiscal, Informe Final de la Misión para la Descentralización y las Finanzas, Bogotá, Presidencia de la República, DNP, 1992.

81. Wiesner, E. "Transferencia, incentivos y la endogeneidad del gasto territorial”, Archivos de Economía 174, DNP, 2002.

82. Wiesner, E. "Fiscal federalism in Latin America, from entitlements to markets", IDB, Washington, D. C., 2003. 
83. Winkler, D. R. "The design and administration of intergovernmental transfers. Fiscal decentralization in Latin America", documento de análisis 235, Banco Mundial, Washington, D.C., 1994.

84. World Bank. World Development Indicators, "Urban population", 2013, data file, [http://data.worldbank.org/].

85. World Bank. "Fiscal Decentralization Indicators", 2001, [http://www1. worldbank.org/publicsector/decentralization/fiscalindicators.htm].

86. World Bank. "Fiscal Decentralization Indicators", 2012, [http:// siteresources.worldbank.org/PUBLICSECTORANDGOVERNANCE/ Resources/285741-1326399585993/8366509-1332861347588/gfsDec2012_indicators_final.xlsx].

87. Zapata, J. G. Las finanzas territoriales en Colombia, Bogotá, Fedesarrollo y CAF, 2009. 